\title{
Synthesis of Benzo[b]furans by Intramolecular C-O Bond Formation Using Iron and Copper Catalysis
}

\author{
Martyn C. Henry and Andrew Sutherland*
}

Cite This: Org. Lett. 2020, 22, 2766-2770

Read Online

ABSTRACT: One-pot processes for the synthesis of benzo[ $b]$ furans from 1-aryl- or 1-alkylketones using nonprecious transition metal catalysts have been developed. Regioselective iron(III)-catalyzed halogenation of the aryl ring, followed by iron- or copper-catalyzed $O$-arylation allowed the synthesis of various structural analogues, including the benzo $[b]$ furan-derived natural products corsifuran $\mathrm{C}$, moracin $\mathrm{F}$, and caleprunin $\mathrm{B}$.

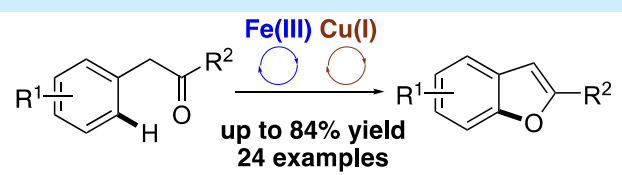

- one-pot procedures - earth-abundant metal catalysis - down to ppm Cu loading $\bullet$ air tolerant transformations
$\mathrm{T}_{\mathrm{s}}$ he benzo[b]furan ring system is a privileged structure, found in a wide range of natural products and pharmaceutically active compounds. ${ }^{1} 2$-Substituted analogues, in particular, have been isolated from various plant and marine sources, as well as bacterial and fungal organisms and have been shown to have activity as antimicrobial, antifungal, and anti-inflammatory agents.

Due to the medical importance of benzo[b]furans, there has been significant efforts in developing new synthetic methods for their preparation, ${ }^{2}$ including transition-metal-catalyzed processes. $^{3-5}$ A common approach is the reaction of 2-halophenols with alkynes via a Sonogashira reaction, followed by transitionmetal-catalyzed $\mathrm{O}$-heterocyclization. ${ }^{2 \mathrm{a}} \mathrm{Li}$ and co-workers have shown that these steps can be combined in a one-pot process using a catalytic system composed of $\left[\mathrm{Pd}\left(\eta^{3}-\mathrm{C}_{3} \mathrm{H}_{5}\right) \mathrm{Cl}\right]_{2}$ and a tetraphosphine ligand (Scheme 1a). ${ }^{4 \mathrm{c}}$ Low catalyst loading $(<0.1 \mathrm{~mol} \%)$ could be used with a wide range of 2-chloro-, 2 bromo-, and 2-iodophenol substrates. Although less common,

Scheme 1. Selected Metal-Catalyzed Approaches for the Synthesis of Benzo $[b]$ furans

a) Pd-catalyzed Sonogashira and cyclization of 2-halophenols and alkynes.

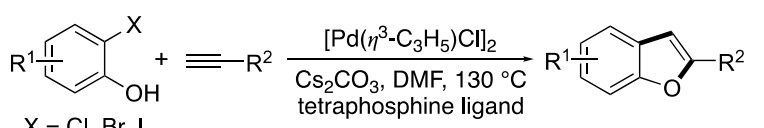

$\mathrm{X}=\mathrm{Cl}, \mathrm{Br}$, I

b) Pd-catalyzed intramolecular O-arylation of enolates.

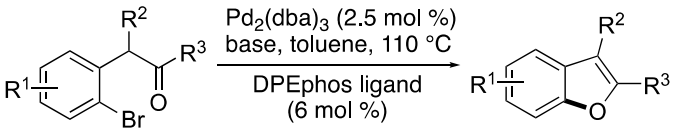

c) This work: Fe and Cu catalyzed activation and cyclization.

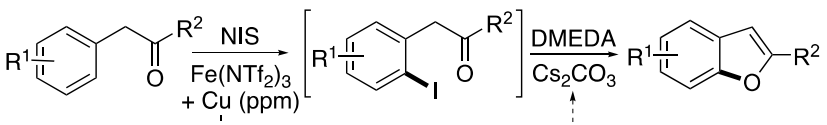

preparation of benzo[ $b]$ furans by formation of the $\mathrm{C}_{7 \mathrm{a}}-\mathrm{O}$ bond has also been reported via metal-catalyzed cyclization of 1-(2haloaryl)ketones. ${ }^{5}$ A general process was reported by Willis and co-workers, who showed that enolates of 1-(2-bromoaryl)ketones were effective substrates for palladium-catalyzed $O$ heterocyclization and the preparation of 2,3-disubstituted benzo $[b]$ furans (Scheme $1 \mathrm{~b}$ ). ${ }^{\text {5a }}$ Similar transformations that use nonprecious transition metal catalysts have also been described. ${ }^{5 \mathrm{~b}-\mathrm{f}}$ Whereas high-temperature reactions, under basic conditions involving copper(I) salts, are typically used, Bolm and co-workers reported that this transformation could also be catalyzed by iron(III) chloride. ${ }^{5 f}$

Although several methods for the synthesis of benzo $[b]$ furans through $\mathrm{C}_{7 \mathrm{a}}-\mathrm{O}$ bond formation have been described, these require prehalogenated 1 -arylketone starting materials. We recently reported the use of iron(III) triflimide as a super Lewis acid for the activation of $N$-halosuccinimides and the subsequent regioselective halogenation of arenes. ${ }^{6}$ This process could also be combined with copper-catalyzed inter- and intramolecular $\mathrm{C}-\mathrm{N}$ and $\mathrm{C}-\mathrm{O}$ bond forming reactions for the preparation of anilines, aryl amides, and benzannulated heterocycles. ${ }^{7}$ Based on this research program, we envisaged a one-pot approach for the preparation of highly substituted benzo[ $b]$ furans from simple 1aryl- or 1-alkylketones, involving regioselective iron(III)catalyzed halogenation, followed by metal-mediated $\mathrm{O}$-arylation. We now report the development of various one-pot processes for the synthesis of benzo[b]furans. As well as demonstrating the use of parts per million (ppm) copper loading to perform $\mathrm{C}-\mathrm{O}$ cyclization (Scheme 1c), we report that both steps can also be catalyzed using a single iron salt.

Received: February 27, 2020

Published: March 18, 2020 
The 1-aryl- and 1-alkylketones used in this study were readily accessed from commercially available phenylacetic acids. For example, the synthesis of 1 -arylketone $3 a$, used to optimize the one-pot processes, was prepared in two steps (Scheme 2). 3-

Scheme 2. Synthesis of 1-Arylketone $3 a^{a}$

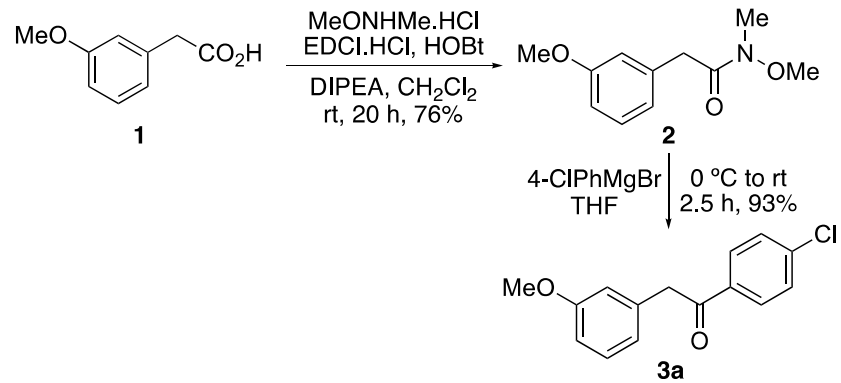

${ }^{a}$ Isolated yields.

Methoxyphenylacetic acid (1) was converted to Weinreb amide 2 under standard conditions, and subsequent reaction with 4chlorophenylmagnesium bromide allowed the efficient, scalable synthesis of $3 a$.

Initial development of a one-pot synthesis of benzo $[b]$ furans focused on iron(III)-catalyzed halogenation and copper(I)catalyzed cyclization of 1-arylketone $3 \mathbf{a}$ (Table 1). Iron

Table 1. Optimization Studies for the Iron- and CopperCatalyzed Synthesis of Benzo $[b]$ furan $4 a^{a}$

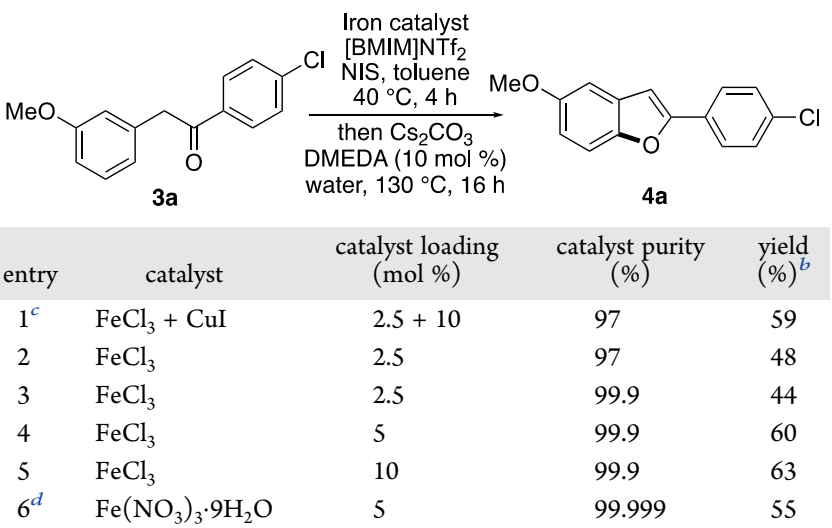

${ }^{a}$ All reactions used [BMIM] $\mathrm{NTf}_{2}$ (3 times the amount of Fe catalyst).

${ }^{b}$ Isolated yields. ${ }^{c}$ Conducted using CuI (10 mol \%) and DMEDA (20 mol \%). ${ }^{d}$ Reaction times for each step was 5 and $20 \mathrm{~h}$.

triflimide (2.5 mol \%), generated from iron(III) chloride and the ionic liquid, [BMIM] $\mathrm{NTf}_{2}$, was used for activation of $\mathrm{N}$ iodosuccinimide (NIS) and subsequent iodination of 3a (entry 1). ${ }^{1} \mathrm{H}$ NMR studies confirmed that despite the metaarylethanone substituent, iron(III)-catalyzed iodination proceeded exclusively at the position para to the methoxy activating group. The second stage of the one-pot process was conducted using copper(I) iodide (10 mol \%) and DMEDA (20 mol \%), which gave benzo[ $b]$ furan $4 a$ in $59 \%$ yield.

As Bolm and co-workers reported that iron(III) could be used for the $O$-cyclization of 1-(2-bromoaryl)ketones, ${ }^{5 f}$ we next investigated whether a single iron salt could be used to perform both iodination and cyclization steps during a one-pot process. This goal became more challenging when we were made aware that most grades of commercial $\mathrm{FeCl}_{3}$ contain various levels of metal contaminants, including sufficient copper to catalyze the
O-arylation step (e.g., $\mathrm{FeCl}_{3}$ with $99.9 \%$ purity contains 31.1 ppm of $\mathrm{Cu}) .{ }^{8}$ However, this presented an opportunity to develop a one-pot process using a single iron complex in which the residual ppm levels of copper could be used to catalyze the cyclization step. The one-pot process was repeated using only $\mathrm{FeCl}_{3}$, with either 97 or $99.9 \%$ purity, which gave benzo $[b]$ furan 4a in 48 and 44\% yields, respectively (Table 1, entries 2 and 3 ). To verify that ppm loading of copper could catalyze the heterocyclization of 1-(2-haloaryl)ketones, we performed the single-step cyclization with the iodide of $3 \mathrm{a}$ using $\mathrm{CuI}(0.001$ mol \%, $14 \mathrm{ppm}) .{ }^{9}$ This gave benzo[b]furan $4 \mathrm{a}$ in $55 \%$ yield. Thus, in the one-pot process, we believe that whereas iron(III) performs the iodination step, the ppm loading of copper is responsible for the intramolecular $O$-arylation step. To improve the yield of this one-pot process, catalyst loading was next investigated. Using $\mathrm{FeCl}_{3}$ (99.9\% purity) at $5 \mathrm{~mol} \%$ loading gave $4 \mathrm{a}$ in $60 \%$ yield (entry 4 ). Increasing the catalyst loading further (entry 5 ) did not lead to substantially higher yields, and so $5 \mathrm{~mol} \%$ was deemed the optimal amount for subsequent studies.

To determine whether iron(III) could catalyze both halogenation and cyclization steps, the one-pot process was performed using an ultrapure iron(III) salt. As ultrapure iron(III) chloride was not commercially available, iron(III) nitrate nonahydrate $(99.999 \%$ purity), which contains no copper, was investigated. Initial trials demonstrated that in combination with $[\mathrm{BMIM}] \mathrm{NTf}_{2}, \mathrm{Fe}\left(\mathrm{NO}_{3}\right)_{3} \cdot 9 \mathrm{H}_{2} \mathrm{O}$ was an effective Lewis acid for regioselective halogenation, with complete conversion to the iodide intermediate after $5 \mathrm{~h}$. Then, using only this complex $(5 \mathrm{~mol} \%)$ for the entire one-pot process gave benzo[ $b]$ furan $4 \mathrm{a}$ in $55 \%$ yield (Table 1 , entry 6 ). To verify that iron(III) was responsible for catalysis of the cyclization step, control reactions were performed. For example, a reaction in which the iodide of $3 \mathbf{a}$ was treated with DMEDA $(10 \mathrm{~mol} \%), \mathrm{Cs}_{2} \mathrm{CO}_{3}$ in a mixture of toluene and water, under standard cyclization conditions $\left(130{ }^{\circ} \mathrm{C}\right)$ resulted in no conversion to benzo[b]furan $4 \mathrm{a}$. This result confirmed that the $\mathrm{C}-\mathrm{O}$ bond forming step (entry 6) is catalyzed by iron(III) and not due to the introduction of ppm amounts of copper with the addition of reagents and solvents (e.g., water) during the second step.

Having developed three different one-pot processes involving various copper loadings (zero, ppm, and $10 \mathrm{~mol} \%$ ), the scope of these with a range of 1-arylketones was next studied. Initially, the one-process involving $\mathrm{Fe}\left(\mathrm{NO}_{3}\right)_{3} \cdot 9 \mathrm{H}_{2} \mathrm{O}$ that uses iron(III) to catalyze both steps was performed with electron-deficient ( $p$ $\left.\mathrm{CF}_{3} \mathrm{Ph}, 3 \mathbf{e}\right)$ and electron-rich ( $\left.p-\mathrm{MeOPh}, 3 \mathbf{j}\right)$ 1-arylketone substrates (Scheme 3$)$. This gave benzo[b]furan $4 \mathbf{e}$ and the natural product, corsifuran C $(\mathbf{4 j})$ (from Corsinia coriandrina), ${ }^{10}$ in 55 and $41 \%$ yields, respectively. These results confirm that a single iron complex can be used to catalyze both steps and access various benzo $[b]$ furans. However, due to the moderate yields (also, 55\% for 4a), the requirement of an ultrapure metal salt, and the avoidance of copper contaminants, we felt that the other one-pot processes that use standard grades of iron(III) chloride would be more synthetically useful.

The one-pot process involving $\mathrm{FeCl}_{3}$ (99.9\% purity) to catalyze the iodination step and then residual copper (31.1 ppm) to catalyze the $O$-heterocyclization was next investigated for the preparation of biologically important 2 -arylbenzo[b]furans (Scheme 3). 1-Arylketone substrates bearing electron-deficient and electron-rich aryl groups, as well as various $o-, m$-, and $p$ substituents were found to be effective substrates, allowing the 
Scheme 3. Scope of One-Pot Synthesis of Benzo[b]furans $4^{a, b}$

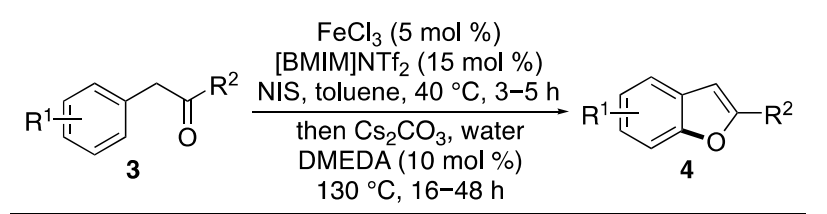

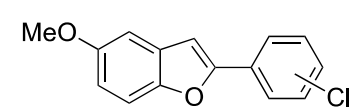

4a $(4-\mathrm{Cl}), 60 \%(55 \%)^{c}$

$4 \mathrm{~b}(3-\mathrm{Cl}), 62 \%$

4 c $(2-\mathrm{Cl}), 60 \%$

$\mathrm{MeO}$

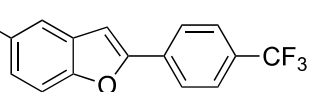

4 e, $73 \%(55 \%)^{c}$<smiles>COc1ccc2oc(-c3ccc([N+](=O)[O-])cc3)cc2c1</smiles>

$4 \mathrm{~g}, 63 \%$<smiles>COc1ccc2oc(-c3ccc(C)cc3)cc2c1</smiles>

$4 i, 68 \%$<smiles>COc1ccc2oc(-c3c(C)cc(C)cc3C)cc2c1</smiles>

4k, $75 \%$<smiles></smiles><smiles>COc1ccc(-c2cc3cc4c(cc3o2)OCO4)cc1</smiles>

${ }^{a}$ Iron(III) chloride with $99.9 \%$ purity was used. ${ }^{b}$ Isolated yields. ${ }^{c}$ Isolated yields using $\mathrm{Fe}\left(\mathrm{NO}_{3}\right)_{3} \cdot 9 \mathrm{H}_{2} \mathrm{O}(5 \mathrm{~mol} \%)$.

synthesis of a range of structural analogues $4 a-4 n$ in $55-75 \%$ yields. This included the efficient preparation of corsifuran $\mathrm{C} \mathbf{4 j}$ in $74 \%$ yield.

This one-pot process was also used to investigate the synthesis of more challenging benzo[ $b]$ furan targets. This included less reactive 1-arylketones with amino-substituted aryl rings or bearing alkylketone side chains (Scheme 4). Although some of the benzo[ $b]$ furans were formed using this one-pot process, the cyclization step with ppm loading of copper required a longer reaction time $(>48 \mathrm{~h})$, resulting in low yields $(<40 \%)$. For this reason, the synthesis of these targets was investigated using the one-pot process involving $\mathrm{CuI}(10 \mathrm{~mol} \%)$. Following a brief optimization study of the original one-pot process (Table 1, entry 1), the use of $\mathrm{FeCl}_{3}$ (97\% purity) at $5 \mathrm{~mol} \%$ loading, followed by $\mathrm{CuI}(10 \mathrm{~mol} \%)$, proved most effective for these substrates. Amino-substituted benzo[ $b]$ furans $\mathbf{6 a}$ and $\mathbf{6 b}$ with synthetically useful protecting groups were prepared in 48 and $65 \%$ yields, respectively. Substrates with alkylketone (5c and $\mathbf{5 d}$ ) or aldehyde (5e) side chains were also tolerated and gave the corresponding benzo[ $[b]$ furans in moderate to good yields. Cyclic ketones $(\mathbf{5} \mathbf{f}-\mathbf{5 h})$ were also found to be substrates for this one-pot process, allowing the effective preparation of polycyclic benzo[b]furans $\mathbf{6 f}-\mathbf{6 h}$. This one-pot process was also used for the gram-scale synthesis of corsifuran C (4j). Whereas the use of ppm loading of copper for the heterocyclization step on a small scale gave $4 \mathbf{j}$ in $74 \%$ yield (Scheme 3 ), for a larger-scale reaction,
Scheme 4. One-Pot Synthesis of Benzo[b]furans $4 j$ and $6^{a, b}$

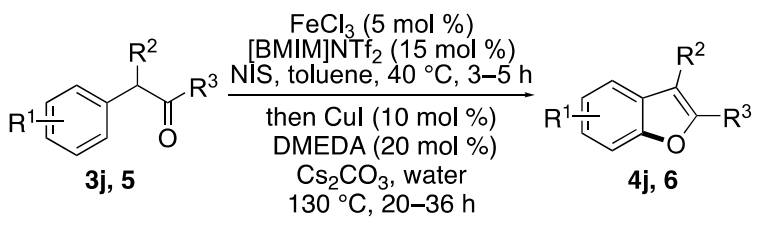

RHN

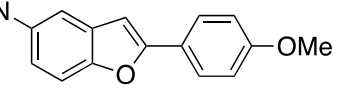

$6 \mathbf{a}(\mathrm{R}=\mathrm{Cbz}), 48 \%$

$6 b(R=B o c), 65 \%$<smiles>CCc1cc2cc(OC)c(OC)cc2o1</smiles>

6d, $64 \%$<smiles>COc1ccc2oc3c(c2c1)CCCC3</smiles>

6f, $53 \%$

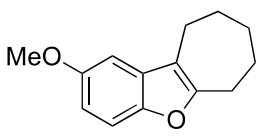

6 h, $57 \%$

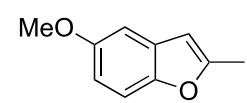

$6 c, 54 \%$<smiles>COc1cc2ccoc2cc1OC</smiles>

$6 e, 40 \%$<smiles>COc1ccc2oc3c(c2c1)CCc1ccccc1-3</smiles>

$6 g, 61 \% c$<smiles>COc1ccc(-c2cc3cc(OC)ccc3o2)cc1</smiles>

Corsifuran C (4j), 84\%

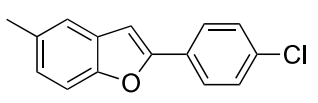

$6 \mathbf{i}, 26 \%{ }^{d}$

${ }^{a}$ Iron(III) chloride with $97 \%$ purity was used. ${ }^{b}$ Isolated yields. ${ }^{c}$ Iodination step was performed at $50{ }^{\circ} \mathrm{C}$ for $6 \mathrm{~h}$. ${ }^{d}$ Iodination step done separately using [BMIM] $\mathrm{NTf}_{2}$ as solvent and at $70{ }^{\circ} \mathrm{C}$ for $16 \mathrm{~h}$.

the use of $\mathrm{CuI}(10 \mathrm{~mol} \%)$ resulted in a more efficient reaction with the isolation of corsifuran $C(4 \mathbf{j})$ in $84 \%$ yield. It should be noted that this $\mathrm{C}_{7 \mathrm{a}}-\mathrm{O}$ bond forming approach does have limitations, ${ }^{11}$ as shown by the synthesis of benzo[b]furan $6 i$. Our previous studies have shown that electron-rich arenes are required for regioselective and efficient iron(III)-catalyzed halogenations. ${ }^{6,7}$ Iodination of unactivated 3-methylphenylsubstituted 1-arylketone $5 \mathbf{i}$ required forcing conditions $\left(70{ }^{\circ} \mathrm{C}\right.$ for $16 \mathrm{~h}$ ), yielding a 4:1 mixture of desired 6-iodo and undesired 4-iodo regioisomers. Copper-catalyzed cyclization of the mixture led to the isolation of $6 \mathrm{i}$ in $26 \%$ yield, over the two steps.

Although these one-pot processes are most effective for the preparation of electron-rich benzo[b]furans, this type of benzannulated system is widely found in pharmaceutically important compounds and natural products (e.g., corsifuran C, $4 j)$. To further demonstrate this, a number of benzo $[b]$ furans prepared in this study were converted to target compounds (Scheme 5). For example, the nitro group of analogue $\mathbf{4 g}$ was reduced with tin dichloride in $90 \%$ yield to give amine 7 , a nanomolar affinity agent of amyloid plaque. ${ }^{12}$ Removal of the silyl protecting groups of benzo[b]furan $4 \mathrm{~m}$ with TBAF, under standard conditions, gave moracin $\mathrm{F}$ (8), an antifungal phytoalexin, isolated from the tissue of mulberry shoots infected with Fusarium solani. ${ }^{13,14}$ Finally, allylic oxidation of benzo[b]furan 6d with selenium dioxide gave caleprunin B (9), a natural 2 -acetylbenzo[b]furan, isolated from both Eupatorium sternbergianum and Calea berteriana. ${ }^{15,16}$

In summary, we have developed new one-pot processes for the synthesis of benzo[b] furans from 1-aryl- or 1-alkylketones, using earth-abundant, nonprecious transition metal catalysts for 
Scheme 5. Synthesis of Biologically Active Benzo[b]furans and Natural Products ${ }^{a}$
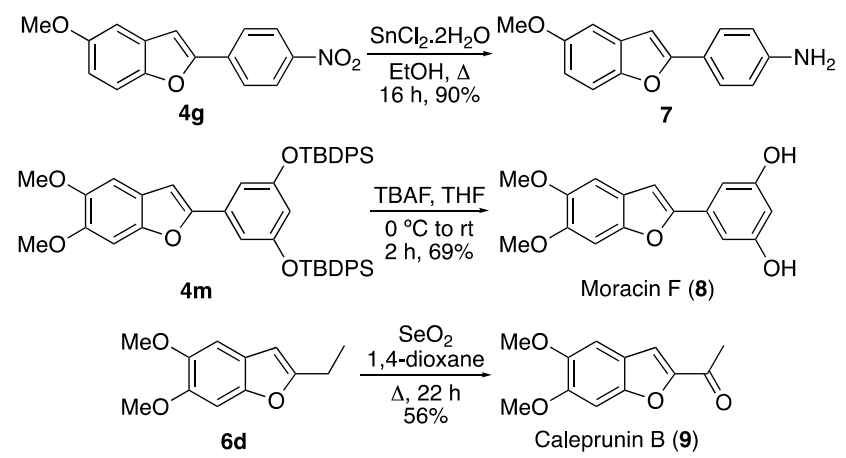

${ }^{a}$ Isolated yields.

aryl $\mathrm{C}-\mathrm{H}$ halogenation and then intramolecular $\mathrm{O}$-arylation. Although, in principle, iron(III) can be used to perform each step in a tandem catalytic process, the use of copper at either ppm or $10 \mathrm{~mol} \%$ loading was found to be more effective, leading to the synthesis of a wide range of structural analogues, including a number of pharmaceutically active targets and natural products. Work is currently underway to discover new onepot, transition-metal-catalyzed processes for the preparation of other benzannulated heterocycles.

\section{ASSOCIATED CONTENT}

\section{SI Supporting Information}

The Supporting Information is available free of charge at https://pubs.acs.org/doi/10.1021/acs.orglett.0c00754.

Experimental procedures, characterization data, NMR spectra of all compounds (PDF)

\section{AUTHOR INFORMATION}

\section{Corresponding Author}

Andrew Sutherland - WestCHEM, School of Chemistry, University of Glasgow, Glasgow G12 8QQ, United Kingdom; (1) orcid.org/0000-0001-7907-5766;

Email: andrew.sutherland@glasgow.ac.uk

\section{Author}

Martyn C. Henry - WestCHEM, School of Chemistry, University of Glasgow, Glasgow G12 8QQ, United Kingdom

Complete contact information is available at: https://pubs.acs.org/10.1021/acs.orglett.0c00754

\section{Notes}

The authors declare no competing financial interest.

\section{ACKNOWLEDGMENTS}

Financial support from EPSRC (Ph.D. studentship to M.C.H., $\mathrm{EP} / \mathrm{M} 508056 / 1)$ and the University of Glasgow is gratefully acknowledged.

\section{REFERENCES}

(1) For reviews of biologically active benzo[b]furans, see: (a) Simonetti, S. O.; Larghi, E. L.; Bracca, A. B. J.; Kaufman, T. S. Angular Tricyclic Benzofurans and Related Natural Products of Fungal Origin. Isolation, Biological Activity and Synthesis. Nat. Prod. Rep. 2013, 30, 941-969. (b) Hiremathad, A.; Patil, M. R.; Chethana, K. R.; Chand, K.; Santos, M. A.; Keri, R. S. Benzofuran: An Emerging Scaffold for Antimicrobial Agents. RSC Adv. 2015, 5, 96809-96828. (c) Radadiya, A.; Shah, A. Bioactive Benzofuran Derivatives: An Insight on Lead Developments, Radioligands and Advances of the Last Decade. Eur. J. Med. Chem. 2015, 97, 356-376.

(2) For general reviews of benzo[b]furan synthesis, see: (a) Godoi, B.; Schumacher, R. F.; Zeni, G. Synthesis of Heterocycles via Electrophilic Cyclization of Alkynes Containing Heteroatom. Chem. Rev. 2011, 111, 2937-2980. (b) Katritzky, A. R.; Rachwal, S. Synthesis of Heterocycles Mediated by Benzotriazole. 2. Bicyclic Systems. Chem. Rev. 2011, 111, 7063-7120. (c) Heravi, M. M.; Zadsirjan, V.; Hamidi, H.; Tabar Amiri, P. H. Total Synthesis of Natural Products Containing Benzofuran Rings. RSC Adv. 2017, 7, 24470-24521. (d) Miao, Y.-h.; Hu, Y.-h.; Yang, J.; Liu, T.; Sun, J.; Wang, X.-j. Natural Source, Bioactivity and Synthesis of Benzofuran Derivatives. RSC Adv. 2019, 9, 27510-27540.

(3) For selected reviews of benzo[b]furan synthesis using metal catalysis, see: (a) Wu, X.-F.; Neumann, H.; Beller, M. Synthesis of Heterocycles via Palladium-Catalyzed Carbonylations. Chem. Rev. 2013, 113, 1-35. (b) Blanc, A.; Bénéteau, V.; Weibel, J.-M.; Pale, P. Silver and Gold-Catalyzed Routes to Furans and Benzofurans. Org. Biomol. Chem. 2016, 14, 9184-9205. (c) Agasti, S.; Dey, A.; Maiti, D. Palladium-Catalyzed Benzofuran and Indole Synthesis by Multiple C-H Functionalizations. Chem. Commun. 2017, 53, 6544-6556.

(4) For recent, selected examples of benzo[b]furan synthesis using metal catalysis, see: (a) Wang, J.-R.; Manabe, K. Hydroxyterphenylphosphine-Palladium Catalyst for Benzo[b]furan Synthesis from 2Chlorophenols. Bifunctional Ligand Strategy for Cross-Coupling of Chloroarenes. J. Org. Chem. 2010, 75, 5340-5342. (b) Yang, J.; Shen, G.; Chen, D. Iron-Catalyzed Synthesis of 2-Arylbenzo[b]furans. Synth. Commun. 2013, 43, 837-847. (c) Zhou, R.; Wang, W.; Jiang, Z.-j.; Wang, K.; Zheng, X.-1.; Fu, H.-y.; Chen, H.; Li, R.-x. One-Pot Synthesis of 2-Substituted Benzo[b]furans via Pd-Tetraphosphine Catalyzed Coupling of 2-Halophenols with Alkynes. Chem. Commun. 2014, 50, 6023-6026. (d) Bosiak, M. J. A. Convenient Synthesis of 2Arylbenzo[ $b]$ furans from Aryl Halides and 2-Halophenols by Catalytic One-Pot Cascade Method. ACS Catal. 2016, 6, 2429-2434. (e) Yamaguchi, M.; Akiyama, T.; Sasou, H.; Katsumata, H.; Manabe, K. One-Pot Synthesis of Substituted Benzo[ $b]$ furans and Indoles from Dichlorophenols/Dichloroanilines Using a Palladium-Dihydroxyterphenylphosphine Catalyst. J. Org. Chem. 2016, 81, 5450-5463. (f) Rehan, M.; Nallagonda, R.; Das, B. G.; Meena, T.; Ghorai, P. Synthesis of Functionalized Benzo $[b]$ furans via Oxidative Cyclization of o-Cinnamyl Phenols. J. Org. Chem. 2017, 82, 3411-3424. (g) Alonso-Maranon, L.; Martinez, M. M.; Sarandeses, L. A.; GomezBengoa, E.; Perez Sestelo, J. Indium(III)-Catalyzed Synthesis of Benzo[b]furans by Intramolecular Hydroxyalkoxylation of orthoAlkynylphenols: Scope and Mechanistic Insights. J. Org. Chem. 2018, 83, 7970-7980. (h) Rong, Z.; Gao, K.; Zhou, L.; Lin, J.; Qian, G. Facile Synthesis of 2-Substituted Benzo[b]furans and Indoles by CopperCatalyzed Intramolecular Cyclization of 2-Alkynyl Phenols and Tosylanilines. RSC Adv. 2019, 9, 17975-17978.

(5) For examples of benzo[ $b]$ furan synthesis by metal-catalyzed $O$ arylation of 1-(2-haloaryl)ketones, see: (a) Willis, M. C.; Taylor, D.; Gillmore, A. T. Palladium-Catalyzed Intramolecular O-Arylation of Enolates: Application to Benzo[b]furan Synthesis. Org. Lett. 2004, 6, 4755-4757. (b) Chen, C.-y.; Dormer, P. G. Synthesis of Benzo[b]furans via CuI-Catalyzed Ring Closure. J. Org. Chem. 2005, 70, 69646967. (c) Carril, M.; SanMartin, R.; Tellitu, I.; Dominguez, E. OnWater Chemistry: Copper-Catalyzed Straightforward Synthesis of Benzo[b]furan Derivatives in Neat Water. Org. Lett. 2006, 8, 14671470. (d) Fang, Y.; Li, C. O-Arylation versus C-Arylation: CopperCatalyzed Intramolecular Coupling of Aryl Bromides with 1,3Dicarbonyls. J. Org. Chem. 2006, 71, 6427-6431. (e) Ackermann, L.; Kaspar, L. T. $\mathrm{TiCl}_{4}$-Catalyzed Indirect Anti-Markovnikov Hydration of Alkynes: Application to the Synthesis of Benzo[b]furans. J. Org. Chem. 2007, 72, 6149-6153. (f) Bonnamour, J.; Piedrafita, M.; Bolm, C. Iron and Copper Salts in the Synthesis of Benzo[b]furans. Adv. Synth. Catal. 2010, 352, 1577-1581.

(6) (a) Racys, D. T.; Warrilow, C. E.; Pimlott, S. L.; Sutherland, A. Highly Regioselective Iodination of Arenes via Iron(III)-Catalyzed 
Activation of N-Iodosuccinimide. Org. Lett. 2015, 17, 4782-4785.

(b) Racys, D. T.; Sharif, S. A. I.; Pimlott, S. L.; Sutherland, A. Silver(I)Catalyzed Iodination of Arenes: Tuning the Lewis Acidity of $\mathrm{N}$ Iodosuccinimide Activation. J. Org. Chem. 2016, 81, 772-780. (c) Mostafa, M. A. B.; Bowley, R. M.; Racys, D. T.; Henry, M. C.; Sutherland, A. Iron(III)-Catalyzed Chlorination of Activated Arenes. J. Org. Chem. 2017, 82, 7529-7537.

(7) (a) Mostafa, M. A. B.; Calder, E. D. D.; Racys, D. T.; Sutherland, A. Intermolecular Aryl C-H Amination Through Sequential Iron and Copper Catalysis. Chem. - Eur. J. 2017, 23, 1044-1047. (b) Henry, M. C.; Senn, H. M.; Sutherland, A. Synthesis of Functionalized Indolines and Dihydrobenzofurans by Iron and Copper Catalyzed Aryl C-N and C-O Bond Formation. J. Org. Chem. 2019, 84, 346-364. (c) Henry, M. C.; McGrory, R.; Faggyas, R. J.; Mostafa, M. A. B.; Sutherland, A. OnePot ortho-Amination of Aryl C-H Bonds using Consecutive Iron and Copper Catalysis. Org. Biomol. Chem. 2019, 17, 4629-4639.

(8) The amount of copper stipulated in the batch analysis of commercial samples of $\mathrm{FeCl}_{3}$ was verified by us, using inductively coupled plasma analysis.

(9) Previous work by the Bolm group (ref 5f) showed that copper (at ppm loading) is more catalytically active than iron for $O$-arylation of 1(2-bromoaryl)ketones. See also: (a) Buchwald, S. L.; Bolm, C. On the Role of Metal Contaminants in Catalyses with $\mathrm{FeCl}_{3}$. Angew. Chem., Int. Ed. 2009, 48, 5586-5587. (b) Larsson, P.-F.; Correa, A.; Carril, M.; Norrby, P.-O.; Bolm, C. Copper-Catalyzed Cross-Couplings with Partper-Million Catalyst Loadings. Angew. Chem., Int. Ed. 2009, 48, 56915693.

(10) von Reu $\beta$, S. H.; König, W. A. Corsifurans A-C, 2Arylbenzofurans of Presumed Stilbenoid Origin from Corsinia coriandrina (Hepaticae). Phytochemistry 2004, 65, 3113-3118.

(11) This study also briefly investigated the synthesis of benzothiophenes and indoles from thioketones and imines, respectively, using similar one-pot processes. However, attempted preparation of an aryl thioketone from ketone $3 \mathrm{a}$ using $\mathrm{P}_{2} \mathrm{~S}_{5}$ or Lawesson's reagent resulted in decomposition. An imine was prepared from the reaction of ketone $3 a$ and $p$-toluidine, but this was not compatible with the iodination step of the one-pot process, resulting in imine hydrolysis.

(12) Ono, M.; Kawashima, H.; Nonaka, A.; Kawai, T.; Haratake, M.; Mori, H.; Kung, M.-P.; Kung, H. F.; Saji, H.; Nakayama, M. Novel Benzofuran Derivatives for PET Imaging of $\beta$-Amyloid Plaques in Alzheimer's Disease Brains. J. Med. Chem. 2006, 49, 2725-2730.

(13) Takasugi, M.; Nagao, S.; Masamune, T.; Shirata, A.; Takahashi, K. Structures of Moracins E, F, G and H, New Phytoalexins from Diseased Mulberry. Tetrahedron Lett. 1979, 20, 4675-4678.

(14) Naik, R.; Harmalkar, D. S.; Xu, X.; Jang, K.; Lee, K. Bioactive Benzofuran Derivatives: Moracins A-Z in Medicinal Chemistry. Eur. J. Med. Chem. 2015, 90, 379-393.

(15) (a) González, A. G.; Fraga, B. M.; Hernandez, M. G.; García, V. P. Eupatarone, A 2-Acetylbenzofuran from Eupatorium Sternbergianum. Phytochemistry 1982, 21, 1826-1827. (b) Ober, A. G.; Fronczek, F. R.; Fischer, N. H. Three Benzofurans and a 1,4-Dioxin Derivative from Calea Species: The Molecular Structures of Calebertin and Caleteucrin. J. Nat. Prod. 1985, 48, 242-248.

(16) del Carmen Cruz, M.; Tamariz, J. An Efficient Synthesis of Benzofurans and their Application in the Preparation of Natural Products of the Genus Calea. Tetrahedron 2005, 61, 10061-10072. 